\title{
Laudatio Guillaume Caumon, Vistelius Award 2009
}

\author{
Jef Caers
}

Received: 31 May 2010 / Accepted: 1 June 2010 / Published online: 15 June 2010

(C) International Association for Mathematical Geosciences 2010

It is a pleasure to introduce to you the 2009 Vistelius Award winner: Guillaume Caumon. Unlike many other awards given by IAMG and other Societies for career achievement, this award is unique in the sense that it is given to a young researcher for his/her potential and promise to become a leader in the field. Consequently, I believe this to be IAMG's most prestigious award as it recognizes in a researcher's early career the mark this person has had on the field. This is a recognition that IAMG believes the researcher will continue to have, rather than the more automatic recognition one is bestowed after a lifetime of scientific contributions.

Achievements and accomplishments are not easily put into numbers and assigned grades, as is done with finals, homework, or even through an awards committee. Stanford University therefore mostly relies on reviews, references, and recommendations in promoting or awarding people, not on counting publications. A single significant publication or idea is worth infinitely more than fifty average ones. Impact of one's research is not measured through impact factors, but by how others in the field perceive the validity of one's work and by how much others use the result of one's research for their own purposes. Guillaume passes these tests with splendor. I would like to quote my distinguished colleague André Journel in 2004 who stated that "Guillaume is the perfect example of what a 21 st-century mathematical geologist should be: a mathematician, a computer scientist, a geostatistician, but above all, a bona fide geologist attached to field work. I consider his 2004 Math Geology (vol. 36, no. 4) paper a cornerstone of mathematical geology where he established formal validity criteria for "legal" numerical representations of a 3D geological model."

J. Caers $(\bowtie)$

Department of Energy Resources Engineering, Stanford University, 367 Panama Street,

Green Earth Sciences 353, Stanford, CA 94305-2220, USA

e-mail: jcaers@stanford.edu 
Having followed in the footsteps of Jean-Laurent Mallet and now leading the gOcad consortium (with over 40 academic and industry members), Guillaume's impact on the practice of mathematical geosciences is almost daily. Guillaume is leading one of the world's largest and most prestigious consortia in the area of geological modeling, having an impact on both academic research and industry practice. How many researchers at his age can claim such an achievement today? Guillaume and I have much in common, starting out as young faculty members, baby-faced in our twenties, having to follow in footsteps of leaders in our field, which, and this not a great secret revealed, are pretty strong-minded persons and not necessarily eager to let go. Personally, I look forward to continuing our already strong collaboration and exchange of ideas/students between the gOcad consortium and the Stanford Center for Reservoir Forecasting. To make use of his landmark contributions on structural restoration, automatic gridding for geomodels, and modeling structural uncertainty while accounting for a large variety of diverse data. I know Guillaume not simply as a "talking" leader, but also as "making-it-happen" leader who does not shy away from getting his hands dirty.

Therefore, Guillaume, on behalf of the International Association for Mathematical Geosciences, we award you the Vistelius Research Award, which will be handed to you by our President, Vera Pawlowsky-Glahn.



IAMG President Prof. Vera Pawlowsky-Glahn (left) presents Prof. Guillaume Caumon (right) with the 2009 Vistelius Award at the Stanford IAMG meeting in August 2009 